\title{
Effects of Salmon Calcitonin on the Concentrations of Monoamines in Periaqueductal Gray in Formalin Test
}

\author{
Kaveh Rahimi1, Javad Sajedianfard1, Ali Akbar Owji2 \\ ${ }^{1}$ Department of Basic Sciences, School of Veterinary Medicine, Shiraz University, Shiraz, Iran \\ ${ }^{2}$ Department of Biochemistry, School of Medicine, Shiraz University of Medical Sciences, Shiraz, Iran
}

Background: The receptors of salmon calcitonin, located on certain areas of the brain such as the periaqueductal gray matter, are responsible for pain modulation.

Aims: The effects of intracerebroventricular injection of salmon calcitonin on the behavioral response to pain and on the levels of monoamines in the periaqueductal gray were explored using a biphasic animal model of pain.

Study Design: Animal experiment.

Methods: A total of 45 male rats were divided into four groups $(n=6)$. Salmon calcitonin was injected into the lateral ventricle of the brain $(1.5 \mathrm{nmol}$, with a volume of $5 \mu \mathrm{L})$. After $20 \mathrm{~min}, 2.5 \%$ formalin was subcutaneously injected into the right leg claw, and pain behavior was recorded on a numerical basis. At the time of the formalin test, the periaqueductal gray area was microdialized. High-performance liquid chromatography method was used to gauge the levels of monoamines and their metabolites.

Results: Intracerebroventricular injections of salmon calcitonin resulted in pain reduction in the formalin test $(\mathrm{p}<0.05)$. The dialysate concentrations of serotonin, dopamine, norepinephrine, 5-hydroxyindoleacetic acid, 3,4-dihydroxyphenylacetic, and 4-hydroxy-3-methoxyphenylglycol increased in the periaqueductal gray area in different phases of the formalin pain test $(\mathrm{p}<0.05)$.

Conclusion: Salmon calcitonin reduced pain by increasing the concentrations of monoamines and the metabolites derived from them in the periaqueductal gray area.

Keywords: Chromatography, formalin test, high-performance liquid, microdialysis, monoamine oxidase, salmon calcitonin
The periaqueductal gray (PAG) area has a key role in descending pain control pathways in the brain stem (1). Downstream signals from the nuclei in the brain stem to the spinal cord constrain the dispatch of pain signals through the spinal cord (2). Monoamines play an important role in antinociceptive systems and have a close proximity to one another in the anesthetic centers of the brain (3). Different regions of the brain receive monoaminergic neurons from the PAG area (4).

The c-cells of the thyroid gland synthesize calcitonin $(5,6)$. Calcitonin may be secreted by some cells in the brain (7). CTRa and $\mathrm{CTRb}$ are two types of calcitonin receptors whose ability to connect to calcitonin is not very different from each other $(8,9)$. Calcitonin has different species. Salmon calcitonin (sCT) receptors in rats have been distributed with a high density in certain brain areas such as the PAG (10-13). The intracerebroventricular injection of calcitonin leads to hypocalcemia, which implies that the nervous system controls the blood calcium (14). SCT, which is a nonopioid peptide, has a particular antinociceptive effect. Injecting calcitonin into the middle part of the PAG in the brain of rats reduce acute pain in the thermal withdrawal test (15). The intracerebroventricular injection of $\mathrm{sCT}$ causes analgesic effects in tail-flick and hot-plate tests (16). When SCT is injected into the brain of mice, the pain caused by the formalin test is reduced (17). Calcitonin provides an interesting analgesic effect in a series of painful conditions. However, the mechanism of its performance is not well-known. In the current research, the objective is to explore the impact of intracerebroventricular injection of $\mathrm{sCT}$ on the level changes of monoamines and the behavioral responses of pain in the PAG area in the formalin pain test.

\section{MATERIALS AND METHODS}

\section{Animals}

In the current research, 45 male Sprague-Dawley rats (250-300 g) were studied. The rats had free access to water and food and were preserved at the temperature of $23 \pm 2{ }^{\circ} \mathrm{C}$ and in a 12-h light/dark cycle. The protocol of the present study was authorized by the Ethics Committee of the School of Veterinary Medicine of Shiraz University, Shiraz, Iran.

In this study, four groups $(n=6)$ were considered. In the first group, serum physiology was injected intracerebroventricularly (with a

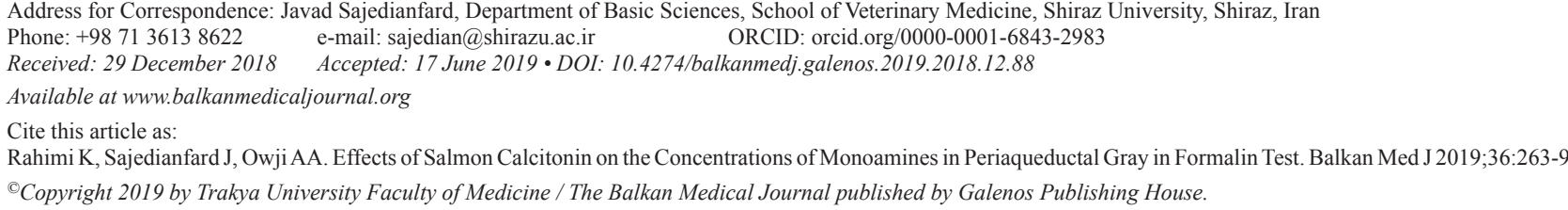


volume of $5 \mathrm{~mL}$ ) and subcutaneously injected in the right leg claw (with a volume of $50 \mathrm{~mL}$ ). In the second group, serum physiology was injected intracerebroventricularly (with a volume of $5 \mathrm{~mL}$ ), and then formalin $(2.5 \%)$ was subcutaneously injected in the right leg claw (with a volume of $50 \mathrm{~mL}$ ). In the third group, $1.5 \mathrm{nmol}$ of $\mathrm{sCT}$ was injected intracerebroventricularly (with a volume of $5 \mathrm{~mL}$ ), and serum physiology was subcutaneously injected in the right leg claw (with a volume of $50 \mathrm{~mL}$ ). In the fourth group, $1.5 \mathrm{nmol}$ of sCT (Sigma-Aldrich, USA) (dissolved in serum physiology) was injected intracerebroventricularly (with a volume of $5 \mathrm{~mL}$ ), and formalin $(2.5 \%)$ was subcutaneously injected in the right leg claw (with a volume of $50 \mathrm{~mL}$ ).

\section{Stereotaxic surgery and microdialysis probe implantation}

The rats were anesthetized by injecting pentobarbital sodium peritoneally $(50 \mathrm{mg} / \mathrm{kg}$ ). The guide cannula (with the coordinates: anteroposterior, -0.8; laterality, +1.5 ; dorsoventral, -3.5) was implanted in the lateral ventricle of the brain. Brain microdialysis probes, with an appropriate length for the PAG area, were constructed based on the Paxinos Atlas. The microdialysis probes were implanted into the PAG area (with the coordinates: anteroposterior, -7.6; laterality, 0.6; dorsoventral, -5.8) (18).

\section{Pain assessment and the microdialysis of the PAG area}

The formalin test is applied for the assessment of pain sensation. In this test, if the rat does not exhibit any unusual behavior, then it is given the score 0 ; if the rat's leg claw is on the floor of the chamber and it does not put its weight on the leg claw, then it is given the score 1; if the rat strikes the floor of the chamber with a leg claw or pulls up its legs to the abdominal area, then it is given the score 2; and lastly, if the rat bites or licks the injection location, then it is given the score 3 (19). The subcutaneous injection of formalin in the leg claw causes a two-phase pain response in the rat. The first 5 minutes ( $\mathrm{min}$ ) after formalin injection comprise the first phase. The second phase begins from the end of the fifteenth min to the end of the sixtieth min. In addition, the interphase starts from the end of the fifth min to the end of the fifteenth min (20).

After $24 \mathrm{~h}$, the rats were put in a microdialysis chamber and were permitted to adjust to the environment for $15 \mathrm{~min}$. A Hamilton syringe $(10 \mu \mathrm{L})$ was used for intracerebroventricular injections of sCT. The pain test was performed $20 \mathrm{~min}$ after the injection of sCT. The PAG area was perfused with artificial cerebrospinal fluid with a flow rate of $2.0 \mu \mathrm{L} / \mathrm{min}$ using a syringe pump (WPI, serum physiology 210). The dialysis samples were gathered at $15 \mathrm{~min}$ intervals $[(\mathrm{S} 1)$, the base sample; (S2), base sample with sCT or serum physiology effects; (S3-S6), the four samples corresponding to the various times of the formalin test with $\mathrm{SCT}$ or serum physiology effects; and (S7, S8), the two samples collected after finishing the pain test]. The artificial cerebrospinal fluid used was a combination of (in mM) $\mathrm{CaCl}_{2}$ (1), $\mathrm{KCl}$ (3), $\mathrm{NaH}_{2} \mathrm{PO}_{4}(1.25), \mathrm{NaCl}$ (114), $\mathrm{NaHCO}_{3}(26), \mathrm{MgSO}_{4}(2), \mathrm{NaOH}(1)$, and glucose (10) with $\mathrm{pH}$ of 7.40 .

\section{Chemical assays}

High-performance liquid chromatography-electrochemical detection method was utilized to determine the concentrations of dopamine, serotonin, norepinephrine, and their metabolites in the dialysis of the PAG area $(n=6)$. After preparing and adding the internal standard $(14.3 \mu \mathrm{L})$, the samples were placed into an highperformance liquid chromatography column (Eurospher reversephase column, 100-5 C18, 250×4.6 mm), a pump (Knauer), and an electrochemical detector (Amperometric Detector EC 3000). The oxidizing potential of the working electrode was set at $+750 \mathrm{mV}$ versus the $\mathrm{Ag} / \mathrm{Cl}$ reference electrode. The mobile phase comprised a combination of ethylenediaminetetraacetic acid (30 mg), sodium phosphate $(8.4 \mathrm{~g})$, 1-octane-sulfonic acid (360 mg), and 16\% methanol (in $1000 \mathrm{~mL}$ of water with high-performance liquid chromatography grade, $\mathrm{pH}=4.5$ ). The mobile phase had a flow rate of $1.0 \mathrm{~mL} / \mathrm{min}$.

\section{Histological substantiation}

The rats were put down using a high dose of diethyl ether (MERK, Germany) after completing each experiment. After $72 \mathrm{~h}$, the rats' brains were placed in $10 \%$ formalin. The positions of the guide cannula in the ventricle and the probes of microdialysis in the PAG area of all the brains were verified according to the Paxinos Atlas (18).

\section{Statistical analysis}

The SPSS software (version 16) was used to analyze the data. According to the distribution and homogeneity of variances, a normalization test was performed on the data (SPSS Kolmogorov-Smirnov test). Since the data were normal, oneway ANOVA was used to evaluate the groups. Duncan's tests were performed as post-hoc analysis. $\mathrm{P}<0.05$ was taken as the significance level.

\section{RESULTS}

\section{Pain assessment}

The results of the pain behavior responses at various phases of the formalin pain test are shown in Table 1.

A significant decrease in the nociceptive behavioral score in the first phase of the formalin pain test was observed in the fourth group $(1.46 \pm 0.08)$ when $\mathrm{sCT}$ was injected into the ventricle of the brain as compared to that of the second group (2.4 \pm 0.05$)$ (Figure 1). A significant decrease in the nociceptive behavioral score when $\mathrm{SCT}$ was injected in interphase of the formalin pain test was observed in the fourth group $(0.35 \pm 0.06)$ as compared to that of the second group (1.92 \pm 0.03 ) (Figure 1). Furthermore, administering sCT through injection in the chronic phases of the formalin pain test of the fourth group $(1.87 \pm 0.03)$ significantly reduced nociception after formalin injection compared to that of the second group $(2.05 \pm 0.01)$ (Figure 1).

\section{The concentrations of monoamines in the PAG area}

The third dialysis samples (S3), which included the artificial cerebrospinal fluid gathered from the PAG area in 0-15 min time intervals after formalin injection, correlated to the first phase and interphase of the formalin pain test. The fourth, fifth, and sixth dialysis samples (S4-S6) obtained within the time intervals of 15-30, 30-45, and 45-60 min, respectively, after formalin injection correlated to the second phase of the formalin pain test. 
TABLE 1. Pain-related behaviors (mean \pm standard deviation) in formalin test

\begin{tabular}{|c|c|c|c|c|c|c|}
\hline & Minute 5 & Minute 10 & Minute 15 & Minute 20 & Minute 25 & Minute 30 \\
\hline Group 1 & $0.13 \pm 0.16^{\mathrm{a}}$ & $0 \pm 0^{\mathrm{a}}$ & $0 \pm 0^{\mathrm{a}}$ & $0 \pm 0^{\mathrm{a}}$ & $0 \pm 0^{\mathrm{a}}$ & $0 \pm 0^{\mathrm{a}}$ \\
\hline Group 2 & $2.41 \pm 0.14^{\mathrm{d}}$ & $1.90 \pm 0.07 \mathrm{c}$ & $1.96 \pm 0.86^{\mathrm{c}}$ & $2.14 \pm 0.19^{c}$ & $2.09 \pm 0.10^{\mathrm{c}}$ & $2.06 \pm 0.69^{c}$ \\
\hline \multirow[t]{2}{*}{ Group 4} & $1.14 \pm 0.22^{b}$ & $0.34 \pm 0.10^{\mathrm{b}}$ & $0.64 \pm 0.20^{\mathrm{b}}$ & $1.58 \pm 0.48^{b}$ & $1.83 \pm 0.32^{b}$ & $1.87 \pm 0.68^{\mathrm{b}}$ \\
\hline & Minute 35 & Minute 40 & Minute 45 & Minute 50 & Minute 55 & Minute 60 \\
\hline Group 3 & $0 \pm 0^{\mathrm{a}}$ & $0 \pm 0^{\mathrm{a}}$ & $0 \pm 0^{\mathrm{a}}$ & $0 \pm 0^{\mathrm{a}}$ & $0 \pm 0^{\mathrm{a}}$ & $0 \pm 0^{\mathrm{a}}$ \\
\hline Group 4 & $1.98 \pm 0.04^{b}$ & $2 \pm 0.03^{b}$ & $2 \pm 0.10^{\mathrm{b}}$ & $1.98 \pm 0.02^{b}$ & $1.98 \pm 0.03^{b}$ & $1.99 \pm 0.13^{b}$ \\
\hline
\end{tabular}

Dissimilar letters (a, b, c, d) indicate significant difference between groups, $(\mathrm{p}<0.05)$.

Group 1: Normal saline was injected intracerebroventricularly and subcutaneously in the hind paw; Group 2: Normal saline was injected intracerebroventricularly, and 2.5\% formalin was

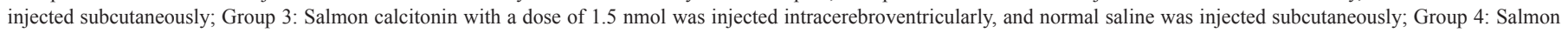
calcitonin with a dose of $1.5 \mathrm{nmol}$ was injected intracerebroventricularly, and $2.5 \%$ formalin was injected subcutaneously

\section{Serotonin}

Serotonin concentrations in groups 1 and 3 did not have significant differences at any of the tested times. The serotonin concentration $(\mathrm{pg} / \mathrm{mL})$ in dialysis sample 3 in the second group $(155.42 \pm 31.12)$ was significantly lower than that of the fourth group $(369.11 \pm 51.92)$ $(\mathrm{p}<0.05)$. Serotonin concentrations in dialysis samples 4 and

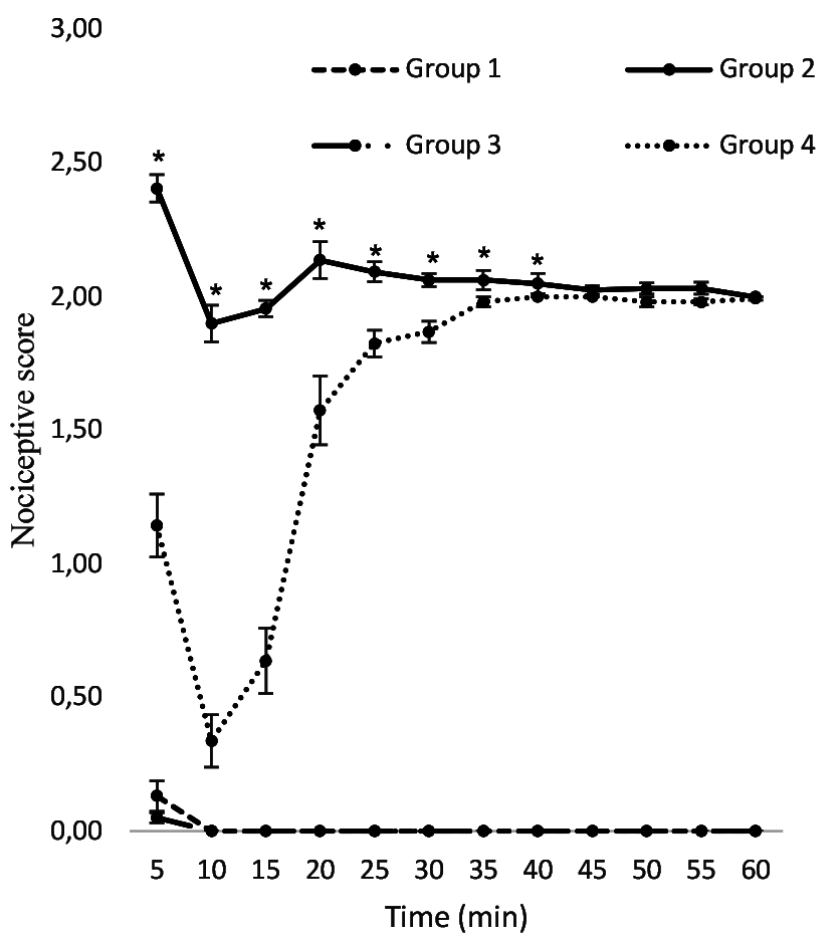

FIG. 1. The nociceptive score in different groups.

[Group 1: Normal saline was injected intracerebroventricularly, and normal saline was injected subcutaneously in the hind paw; Group 2: normal saline was injected intracerebroventricularly, and $2.5 \%$ formalin was injected subcutaneously; Group 3: Salmon calcitonin with a dose of $1.5 \mathrm{nmol}$ was injected intracerebroventricularly, and normal saline was injected subcutaneously; Group 4: Salmon calcitonin with a dose of $1.5 \mathrm{nmol}$ was injected intracerebroventricularly, and $2.5 \%$ formalin was injected subcutaneously]; *Significant differences between groups 2 and $4(\mathrm{p}<0.05)$ (mean \pm standard deviation)
5 in the second group $(101.33 \pm 11.36$ and $90.16 \pm 17.61)$ were significantly lower than those of the fourth group $(198.27 \pm 17.06$ and $136.23 \pm 19.32)(\mathrm{p}<0.05)$. Serotonin concentration in dialysis sample 6 in the second group was lower than that of the fourth group. However, the difference was not significant (Figure 2).

\section{5-Hydroxyindoleacetic acid}

5-Hydroxyindoleacetic acid concentrations did not have significant differences in groups 1 and 3 at any of the time intervals. 5-Hydroxyindoleacetic acid concentration $(\mathrm{pg} / \mathrm{mL})$ in dialysis sample 3 in the second group (1416.142 \pm 79.74$)$ was significantly less than that of the fourth group (6166.580 \pm 16.28$)$ $(\mathrm{p}<0.05)$. 5-Hydroxyindoleacetic acid concentration in dialysis sample 4 in the second group $(1115.312 \pm 66.18)$ was significantly less than that of the fourth group $(2061.548 \pm 40.01)(\mathrm{p}<0.05)$. 5 -Hydroxyindoleacetic acid concentrations in dialysis samples 5 and 6 in the fourth group did not show any significant differences compared to those of the second group (Figure 3).

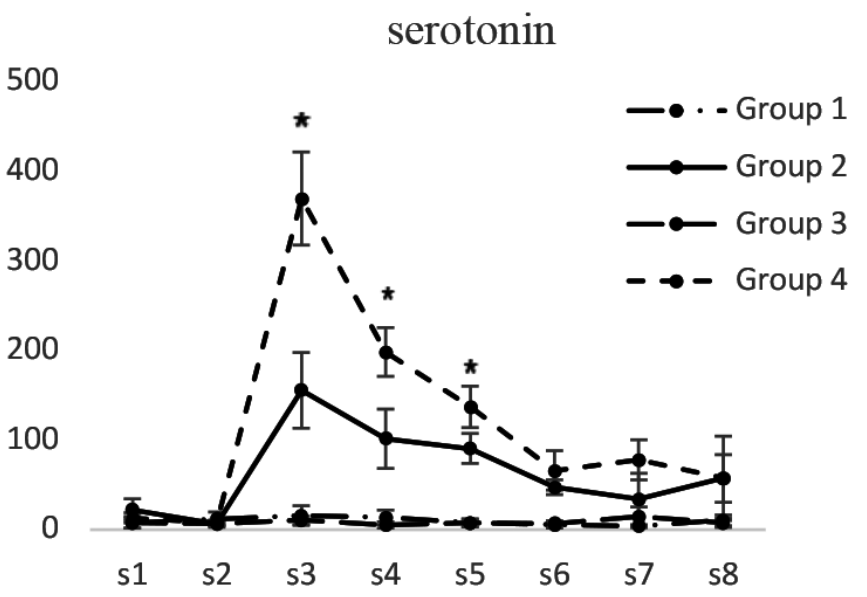

FIG. 2. Concentrations of serotonin in different groups.

[S1 to S8 represent the collected samples of dialysis from the periaqueductal gray at different times. Base sample without medication effect (S1), base sample with medication effect (S2), four samples related to different times of the formalin test (S3-S6), and two samples after completion of formalin test (S7, S8)]; *Significant differences between groups 2 and $4(\mathrm{p}<0.05)$ (mean \pm standard deviation) 


\section{Dopamine}

Dopamine concentrations in groups 1 and 3 did not have significant differences at any of the tested times. Dopamine concentration (pg/ $\mathrm{mL})$ in dialysis sample 3 in the second group (182.25 \pm 32.58$)$ was significantly lower than that of the fourth group (390.119 \pm 12.29$)$ $(\mathrm{p}<0.05)$. Dopamine concentration in dialysis sample 4 in the second group $(88.27 \pm 18.42)$ was lower than that of the fourth group $(183.30 \pm 19.68) \quad(\mathrm{p}<0.05)$. Dopamine concentrations in dialysis samples 5 and 6 in the second group were lower than those of the fourth group. Nevertheless, the difference was not significant (Figure 4).

\section{3,4-Dihydroxyphenylacetic}

3,4-Dihydroxyphenylacetic concentrations in groups 1 and 3 did not have significant differences at any of the time intervals. 3,4-Dihydroxyphenylacetic concentration $(\mathrm{pg} / \mathrm{mL})$ in dialysis sample 3 in the second group $(630.97 \pm 97.02)$ was significantly less than that of the fourth group $(1214.169 \pm 29.01)(p<0.05)$. Dopamine concentration in dialysis sample 4 in the second group (298.76 \pm 38.34$)$ was less than that of the fourth group $(709.166 \pm 40.25) \quad(\mathrm{p}<0.05) . \quad 3,4-D i h y d r o x y p h e n y l a c e t i c$ concentrations in dialysis samples 5 and 6 in the fourth group did not show any significant differences compared to those of the second group (Figure 5).

\section{Norepinephrine}

Norepinephrine concentrations in groups 1 and 3 did not have significant differences at any of the time intervals. Norepinephrine concentration $(\mathrm{pg} / \mathrm{mL})$ in dialysis sample 3 in the second group $(110.34 \pm 19.13)$ was significantly lower than that of the fourth

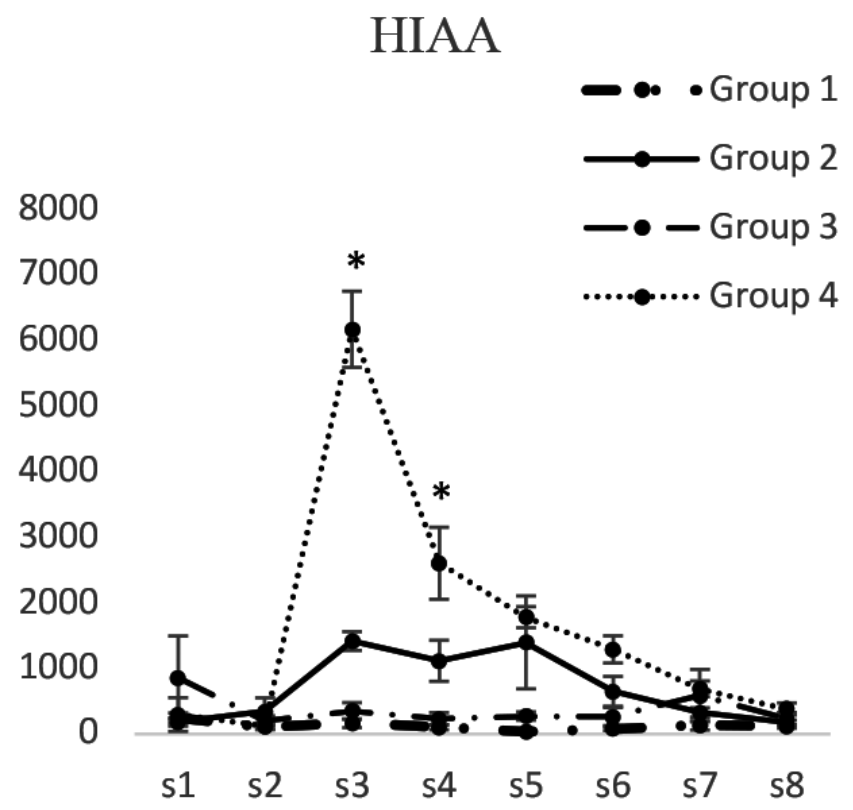

FIG. 3. Concentrations of 5-hydroxyindoleacetic acid in different groups. [S1 to S8 represent the collected samples of dialysis from the periaqueductal gray at different times. Base sample without medication effect (S1), base sample with medication effect (S2), four samples related to different times of the formalin test (S3-S6), and two samples after completion of formalin test (S7, S8)]; *Significant differences between groups 2 and $4(\mathrm{p}<0.05)($ mean \pm standard deviation) group $(213.39 \pm 17.85)(\mathrm{p}<0.05)$. Norepinephrine concentration in dialysis sample 4 in the second group $(53.14 \pm 19.79)$ was lower than that of the fourth group $(140.39 \pm 25.61)(\mathrm{p}<0.05)$ (Figure 6). 4-Hydroxy-3-methoxyphenylglycol

4-Hydroxy-3-methoxyphenylglycol concentrations in groups 1 and 3 did not have significant differences at any of the time intervals. 4-Hydroxy-3-methoxyphenylglycol concentration (pg/ $\mathrm{mL})$ in dialysis sample 3 in the second group (248.51 \pm 41.78$)$ was

\section{Dopamine}

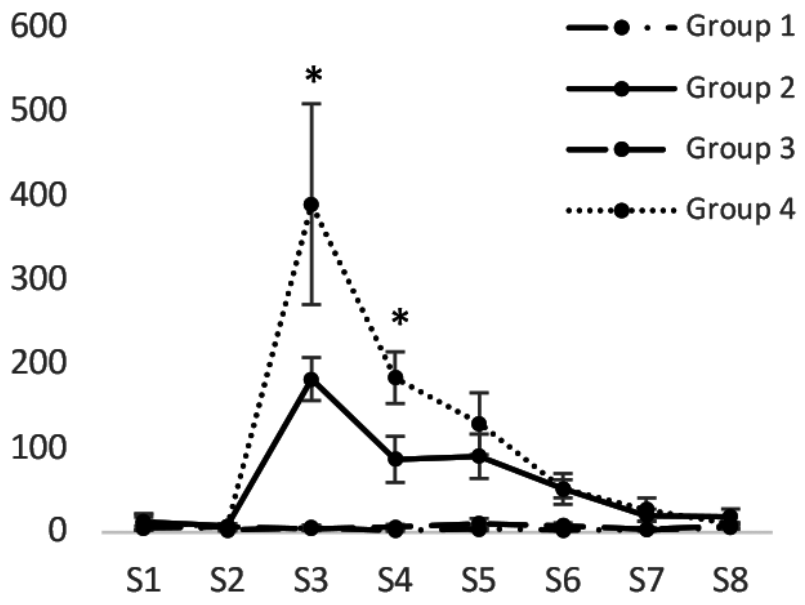

FIG. 4. Concentrations of dopamine in different groups.

[S1 to S8 represent the collected samples of dialysis from the periaqueductal gray at different times. Base sample without medication effect (S1), base sample with medication effect (S2), four samples related to different times of the formalin test (S3-S6), and two samples after completion of formalin test (S7, S8)]; *Significant differences between groups 2 and $4(\mathrm{p}<0.05)$ (mean \pm standard deviation)

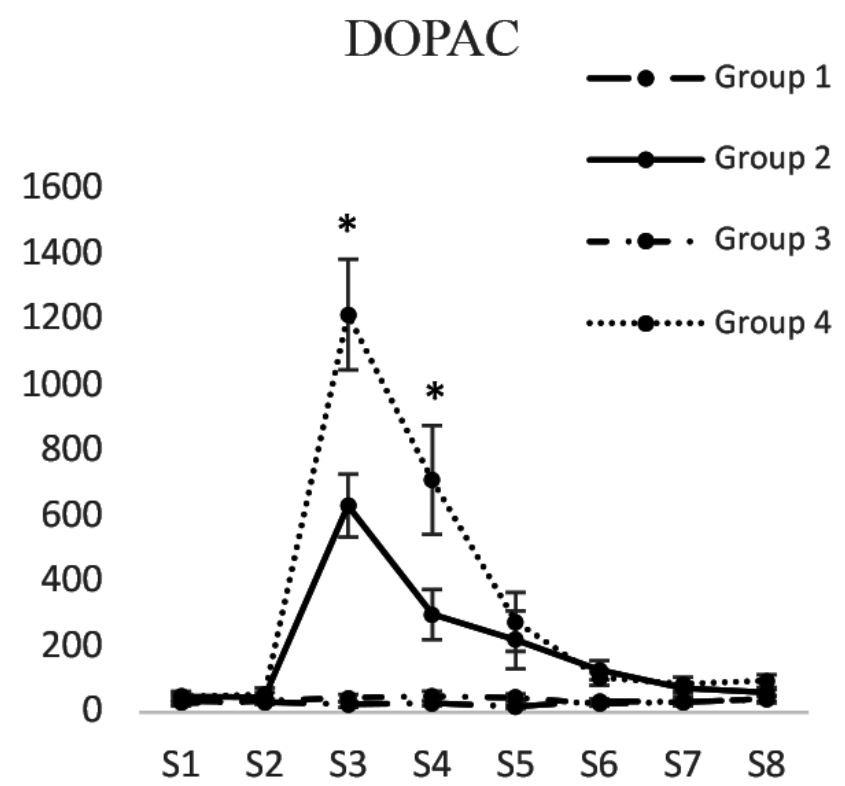

FIG. 5. Concentrations of 3,4-dihydroxyphenylacetic in different groups.

[S1 to S8 represent the collected samples of dialysis from the periaqueductal gray at different times. Base sample without medication effect (S1), base sample with medication effect (S2), four samples related to different times of the formalin test (S3-S6), and two samples after completion of formalin test (S7, S8)]; *Significant differences between groups 2 and $4(\mathrm{p}<0.05)$ (mean \pm standard deviation) 
significantly less than that of the fourth group (514.95 \pm 42.89$)$ $(\mathrm{p}<0.05)$. 4-Hydroxy-3-methoxyphenylglycol concentration in dialysis sample 4 in the second group $(110.13 \pm 10.05)$ was less than that of the fourth group $(213.49 \pm 16.09)(\mathrm{p}<0.05)$. 4-Hydroxy3 -methoxyphenylglycol concentrations in dialysis samples 5 and 6 in the second group were less than those of the fourth group. However, the difference was not significant (Figure 7).

\section{DISCUSSION}

The nociceptive behavioral scores in the first, inter, and second phases of the formalin pain test were significantly reduced by the introduction of sCT through intracerebroventricular injection. sCT increased the concentrations of serotonin, dopamine, norepinephrine,

\section{Norepinephrine}

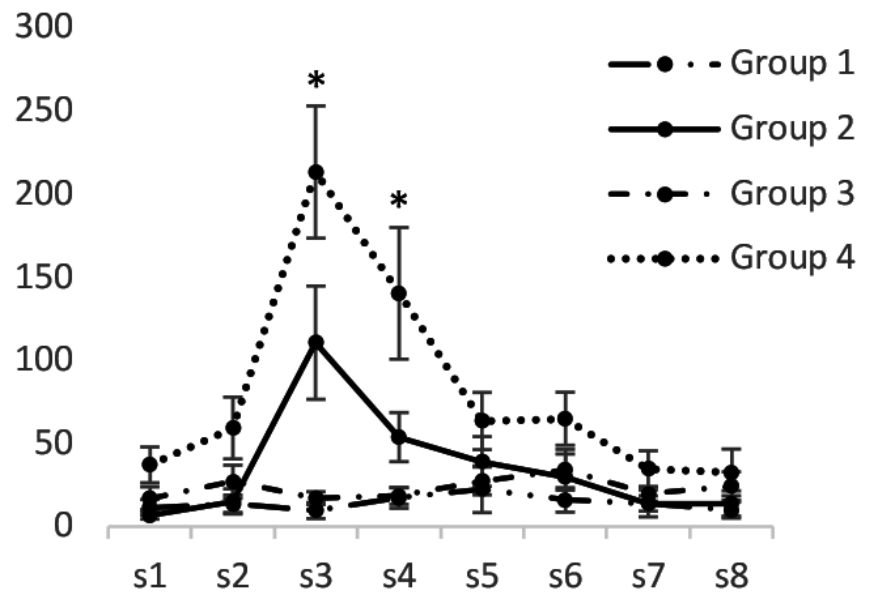

FIG. 6. Concentrations of norepinephrine in different groups.

[S1 to S8 represent the collected samples of dialysis from the periaqueductal gray at different times. Base sample without medication effect (S1), base sample with medication effect (S2), four samples related to different times of the formalin test (S3-S6), and two samples after completion of formalin test (S7, S8)]; *Significant differences between groups 2 and $4(\mathrm{p}<0.05)$ (mean \pm standard deviation)

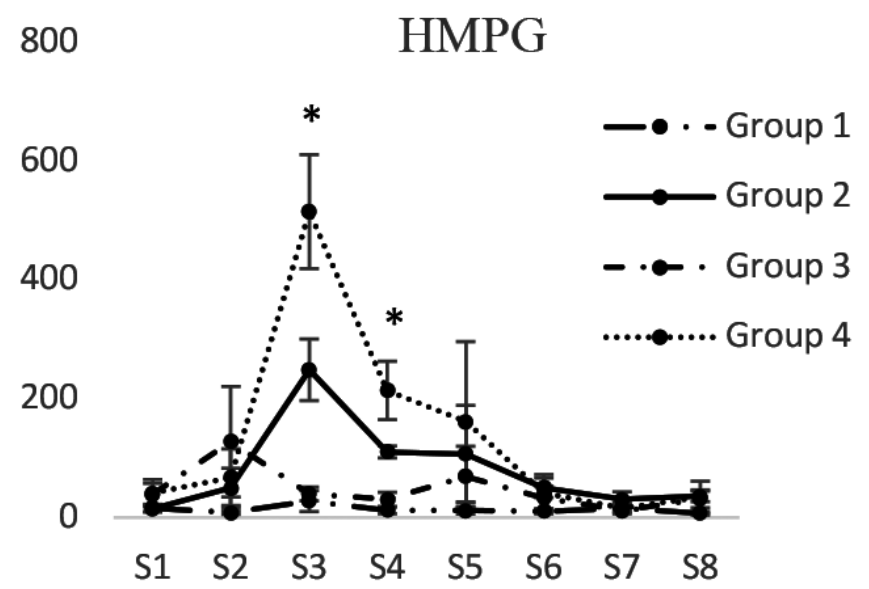

FIG. 7. Concentrations of 4-hydroxy-3-methoxyphenylglycol in different groups. [S1 to S8 represent the collected samples of dialysis from the periaqueductal gray at different times. Base sample without medication effect (S1), base sample with medication effect (S2), four samples related to different times of the formalin test (S3-S6), and two samples after completion of formalin test (S7, S8)]; *Significant differences between groups 2 and $4(\mathrm{p}<0.05)($ mean \pm standard deviation)
5-Hydroxyindoleacetic acid, 3,4-Dihydroxyphenylacetic, and 4-Hydroxy-3-methoxyphenylglycol in the first phase and interphase of the formalin pain test in the PAG area. $\mathrm{SCT}$ also increased the concentrations of serotonin, dopamine, norepinephrine, and their metabolites at the start of the second phase of the formalin pain test. In our previous study, the other calcitonin family peptide (calcitonin gene-related peptide) showed similar effects. Subsequently, intracerebroventricular injection of calcitonin gene-related peptide reduced pain after the injection of formalin. The dialysis of PAG also showed that the intracerebroventricular injection of calcitonin gene-related peptide increased the concentrations of serotonin, norepinephrine, dopamine, 5-Hydroxyindoleacetic acid, 4-Hydroxy-3-methoxyphenylglycol, and 3,4-Dihydroxyphenylacetic in the PAG in the formalin pain test (21).

sCT has analgesic effects on both somatic, such as muscle and bone pains, and visceral pains, such as migraine headaches. $\mathrm{SCT}$ has recently been shown to have the ability to attenuate migraine-like pains by c-fos expression and regulating the release of calcitonin gene-related peptide at different levels (22). eCT, a synthetic derivative of eel calcitonin, exhibits analgesic effects on radicular pain by modulating mRNA-expression of voltage-gated sodium channels. Thus, it can be stated that patients who have radicular pain or need long-term treatments prefer calcitonin for their therapy (23). sCT can inhibit the progression of facet joint syndrome in ovariectomized rats. This potential is ascribed to the inhibitory impacts of $\mathrm{sCT}$ on apoptosis, cartilage metabolism imbalance, and bone remodeling (24). PCR analysis shows that the chronic constriction injury causes the upregulation of tetrodotoxinsensitive Nav.1.3 mRNA. It also leads to the downregulation of mRNA of Nav1.8 and Nav1.9 on the dorsal root ganglion. This will, in turn, enhance the excitability of peripheral nerves. Elcatonin can play an important role in reversing these changes (25).

The results of the current study demonstrated that the intracerebroventricular injection of $\mathrm{SCT}$ significantly decreased nociception during the first phase and interphase of the formalin pain test. Candeletti and Ferri also reported similar effects in mice (17). Different mechanisms have been attributed to the analgesic effects of calcitonin. However, no study has shown a change in the concentration of monoamines in the analgesic systems of the brain. Our results indicate that the concentrations of serotonin, dopamine, norepinephrine, and their metabolites have increased in the PAG area in the first phase and interphase of the formalin pain test. Therefore, it seems that the monoaminergic pathways in the brain mediate the analgesic effects observed in the first phase and interphase of the formalin pain test.

The central serotonergic system might have a role in the analgesic effect caused by calcitonin (26). The intracerebroventricular injection of calcitonin results to the increase in serotonin contents in several regions of the brain (27). Serotonin has an analgesic effect on chronic pain in humans and animals (28). Calcitonin in ovariectomized rats can cause the release of glutamate from C-afferent fibers and can also normalize the expression of sodium channel in damaged peripheral nerves (29). Immunohistochemical studies have also shown that the PAG area that contains dopaminergic neurons is involved in the analgesic system. The injection of the 
dopamine antagonist in the vPAG reduces the analgesic effects of heroin and morphine (30). In addition, norepinephrine and 4-Hydroxy-3-methoxyphenylglycol concentrations are increased in the locus coeruleus in the formalin test (31). locus coeruleus has projections to different areas of the brain such as the PAG (32). In the second phase of the formalin pain test, pain-related behaviors were significantly decreased with the intracerebroventricular injection of sCT. The concentrations of serotonin and 5-Hydroxyindoleacetic acid increased at 15-45 min and 15-30 min time intervals after formalin injection, respectively. The serotonergic system in the PAG area plays a key role in pain modulation. Administering serotonin agonist in the PAG area reduces pain (33). Dopamine and its metabolite (3,4-Dihydroxyphenylacetic) concentrations increased at 15-30 min time interval in the second phase of the formalin pain test. It is noteworthy that a network of dopaminergic neurons is distributed throughout the mesencephalon (34). sCT also increased the concentrations of norepinephrine and its metabolite at 15-30 min time interval after the injection of formalin. Administering norepinephrine in the dorsal part of the PAG area showed that norepinephrine plays a role in pain perception (34).

sCT also has clinical applications. Since the 1970s, sCT has been applied as a nasal spray_or injection to treat osteoporosis and other metabolic bone diseases (35). sCT has also been used for the treatment of postmenopausal osteoporosis. Although the nasal application is less effective than the injectable formulation, it has been more frequently used. sCT increases bone mineral density (36,37). Nasal calcitonin spray has been more effective than gabapentin in treating patients with lumbar spinal stenosis (38). Moreover, nasal sCT has been recommended for ameliorating acute osteoporotic distal radius fractures (39). A study focused on a novel oral $\mathrm{sCT}$ (SMC021) found that this $\mathrm{SCT}$ failed to meet its primary objective, which is to reduce vertebral fractures in postmenopausal women suffering from osteoporosis. The study suggested that more researches should be done on the delivery of peptides (40). Despite its analgesic effects, oral sCT does not have renewable benefits for patients suffering from knee osteoarthritis (41). Studies suggest that calcitonin can alleviate back pains of patients suffering from neuropathic pain or osteoporosis by altering the expression of channels or receptors $(29,42)$.

In the current study, the intracerebroventricular injection of $\mathrm{sCT}$ reduced pain in the formalin pain test. The observed effect may be due to an increase in serotonin, dopamine, norepinephrine, and their metabolites in the PAG area or the related nuclei.

Acknowledgements: The results of this paper are part of a Ph.D. dissertation (research project number: 94GUC6M1293), which was financially supported by the School of Veterinary Medicine, Shiraz University, Shiraz, Iran.

Conflict of Interest: No conflict of interest was declared by the authors.

Financial Disclosure: No financial disclosure was declared by the authors.

\section{REFERENCES}

1. Gebhart GF. Descending modulation of pain. Neuroscience \& Biobehavioral Reviews 2004;27:729-37.

2. Ossipov MH, Dussor GO, Porreca F. Central modulation of pain. J Clin Invest 2010;120:3779-87.
3. García-Ramírez DL, Calvo JR, Hochman S, Quevedo JN. Serotonin, dopamine and noradrenaline adjust actions of myelinated afferents via modulation of presynaptic inhibition in the mouse spinal cord. PLoS One 2014;9:e89999.

4. Kwiat GC, Basbaum AI. Organization of tyrosine hydroxylase- and serotoninimmunoreactive brainstem neurons with axon collaterals to the periaqueductal gray and the spinal cord in the rat. Brain Res 1990;528:83-94.

5. Fischer JA, Born W. Novel peptides from the calcitonin gene: expression, receptors and biological function. Peptides 1985;6(Suppl 3):265-71.

6. Born W, Fischer JA. Calcitonin Gene Products: Molecular Biology, Chemistry, and Actions. Physiology and Pharmacology of Bone. Berlin, Heidelberg: Springer Berlin Heidelberg 1993:569-616.

7. Murakoshi M, Ikeda R, Horiuchi T, Nakayama K, Kurotani R, Osamura RY Immunoreactive pit-1 protein in hyperplastic pars intermedia induced by calcitonin of the rat pituitary gland. Endocr J 2000;47:13-20.

8. Gorn AH, Lin HY, Yamin M, Auron PE, Flannery MR, Tapp DR, et al. Cloning, characterization, and expression of a human calcitonin receptor from an ovarian carcinoma cell line. J Clin Invest 1992;90:1726-35.

9. Kuestner RE, Elrod RD, Grant FJ, Hagen FS, Kuijper JL, Matthewes SL, et al. Cloning and characterization of an abundant subtype of the human calcitonin receptor. Mol Pharmacol 1994;46:246-55.

10. Sexton PM, McKenzie JS, Mason RT, Moseley JM, Martin TJ, Mendelsohn FA. Localization of binding sites for calcitonin gene-related peptide in rat brain by in vitro autoradiography. Neuroscience 1986;19:1235-45.

11. Kruger L, Mantyh PW, Sternini C, Brecha NC, Mantyh CR. Calcitonin gene-related peptide (CGRP) in the rat central nervous system: patterns of immunoreactivity and receptor binding sites. Brain Res 1988;463:223-44.

12. Sexton PM, McKenzie JS, Mendelsohn FA. Evidence for a new subclass of calcitonin calcitonin gene-related peptide binding site in rat brain. Neurochem Int 1988;12:32335 .

13. Sexton PM. Central nervous system binding sites for calcitonin and calcitonin generelated peptide. Mol Neurobiol 1991;5:251-73.

14. Goltzman D, Tannenbaum GS. Induction of hypocalcemia by intracerebroventricular injection of calcitonin: evidence for control of blood calcium by the nervous system. Brain Res 1987;416:1-6.

15. Li Z, Gao Z, Li S, Zhang Y, Xing L, Zhang L, et al. Microinjection of calcitonin in midbrain periaqueductal gray attenuates hyperalgesia in a chronic constriction injury rat model. Iran J Basic Med Sci 2015;18:72-9.

16. Pecile A, Guidobono F, Netti C, Sibilia V, Biella G, Braga PC. Calcitonin generelated peptide: antinociceptive activity in rats, comparison with calcitonin. Regul Pept 1987;18:189-99.

17. Candeletti S, Ferri S. Antinociceptive profile of intracerebroventricular salmon calcitonin and calcitonin gene-related peptide in the mouse formalin test. Neuropeptides 1990;17:93-8.

18. Paxinos GCW. The Rat Brain in Stereotaxic Coordinates. Sydney: Academic Press 2006 .

19. Dubuisson D, Dennis SG. The formalin test: a quantitative study of the analgesic effects of morphine, meperidine, and brain stem stimulation in rats and cats. Pain 1977;4:161-74

20. Coderre TJ, Fundytus ME, McKenna JE, Dalal S, Melzack R. The formalin test: a validation of the weighted-scores method of behavioural pain rating. Pain 1993;54:4350 .

21. Rahimi K, Sajedianfard J, Owji AA. The effect of intracerebroventricular injection of CGRP on pain behavioral responses and monoamines concentrations in the periaqueductal gray area in rat. Iran J Basic Med Sci 2018;21:395-9.

22. Kilinc E, Dagistan Y, Kukner A, Yilmaz B, Agus S, Soyler G, et al. Salmon calcitonin ameliorates migraine pain through modulation of CGRP release and dural mast cell degranulation in rats. Clin Exp Pharmacol Physiol 2018;45:536-46.

23. Terashima Y, Takebayashi T, Jimbo S, Ogon I, Sato T, Ichise N, et al. Analgesic effects of calcitonin on radicular pain in male rats. J Pain Res 2019;12:223-30.

24. Gou Y, Tian F, Kong Q, Chen T, Li H, Lv Q, et al. Salmon Calcitonin Attenuates Degenerative Changes in Cartilage and Subchondral Bone in Lumbar Facet Joint in an Experimental Rat Model. Med Sci Monit 2018;24:2849-57.

25. Ito A, Takeda M, Yoshimura T, Komatsu T, Ohno T, Kuriyama H, et al. Antihyperalgesic effects of calcitonin on neuropathic pain interacting with its peripheral receptors. Mol Pain 2012;8:42. 
26. Clementi G, Prato A, Conforto G, Scapagnini U. Role of serotonin in the analgesic activity of calcitonin. Eur J Pharmacol 1984;98:449-51.

27. Nakhla AM, Nandi Majumdar AP. Calcitonin-mediated changes in plasma tryptophan and brain 5-hydroxytryptamine and acetylcholinesterase activity in rats. Biochem J 1978; 170:445-8.

28. Bobinski F, Ferreira TAA, Córdova MM, Dombrowski PA, da Cunha C, Santo CCDE, et al. Role of brainstem serotonin in analgesia produced by low-intensity exercise on neuropathic pain after sciatic nerve injury in mice. Pain 2015;156:2595-606.

29. Ito A, Yoshimura M. Mechanisms of the analgesic effect of calcitonin on chronic pain by alteration of receptor or channel expression. Mol Pain 2017;13:1744806917720316.

30. Flores JA, El Banoua F, Galán-Rodríguez B, Fernandez-Espejo E. Opiate antinociception is attenuated following lesion of large dopamine neurons of the periaqueductal grey: critical role for D1 (not D2) dopamine receptors. Pain 2004;110:205-14.

31. Sajedianfard J, Khatami S, Semnanian S, Naghdi N, Jorjani M. In vivo measurement of noradrenaline in the locus coeruleus of rats during the formalin test: a microdialysis study. Eur J Pharmacol 2005;512:153-6.

32. Fritschy JM, Grzanna R. Demonstration of two separate descending noradrenergic pathways to the rat spinal cord: evidence for an intragriseal trajectory of locus coeruleus axons in the superficial layers of the dorsal horn. J Comp Neurol 1990;291:553-82.

33. Bartsch T, Knight YE, Goadsby PJ. Activation of 5-HT(1B/1D) receptor in the periaqueductal gray inhibits nociception. Ann Neurol 2004;56:371-81.

34. Estrada VB, Matsubara NK, Gomes MV, Corrêa FM, Pelosi GG. Noradrenaline microinjected into the dorsal periaqueductal gray matter causes anxiolytic-like effects in rats tested in the elevated T-maze. Life Sci 2016;152:94-8.
35. Huang CL, Sun L, Moonga BS, Zaidi M. Molecular physiology and pharmacology of calcitonin. Cell Mol Biol (Noisy-le-grand) 2006;52:33-43.

36. Chesnut CH, Silverman S, Andriano K, Genant H, Gimona A, Harris S, et al. A randomized trial of nasal spray salmon calcitonin in postmenopausal women with established osteoporosis: the prevent recurrence of osteoporotic fractures study. PROOF Study Group. Am J Med 2000;109:267-76.

37. Chesnut CH, Azria M, Silverman S, Engelhardt M, Olson M, Mindeholm L. Salmon calcitonin: a review of current and future therapeutic indications. Osteoporos Int 2008;19:479-91.

38. Haddadi K, Asadian L, Isazade A. Effects of Nasal Calcitonin vs. Oral Gabapentin on Pain and Symptoms of Lumbar Spinal Stenosis: A Clinical Trial Study. Clin Med Insights Arthritis Musculoskelet Disord 2016;9:133-8.

39. Karponis A, Rizou S, Pallis D, Zafeiris CP, Georgiou DF, Galanos A, et al. Analgesic effect of nasal salmon calcitonin during the early post-fracture period of the distal radius fracture. J Musculoskelet Neuronal Interact 2015;15:186-9.

40. Henriksen K, Byrjalsen I, Andersen JR, Bihlet AR, Russo LA, Alexandersen P, et al. A randomized, double-blind, multicenter, placebo-controlled study to evaluate the efficacy and safety of oral salmon calcitonin in the treatment of osteoporosis in postmenopausal women taking calcium and vitamin D. Bone 2016;91:122-9.

41. Karsdal MA, Byrjalsen I, Alexandersen P, Bihlet A, Andersen JR, Riis BJ, et al Treatment of symptomatic knee osteoarthritis with oral salmon calcitonin: results from two phase 3 trials. Osteoarthritis Cartilage 2015;23:532-43.

42. Knopp-Sihota JA, Newburn-Cook CV, Homik J, Cummings GG, Voaklander D. Calcitonin for treating acute and chronic pain of recent and remote osteoporotic vertebral compression fractures: a systematic review and meta-analysis. Osteoporos Int 2012;23:17-38. 